ASTHMA

\title{
Epithelial stress and structural remodelling in childhood asthma
}

\author{
I A Fedorov, S J Wilson, D E Davies, S T Holgate
}

Thorax 2005;60:389-394. doi: 10.1136/thx.2004.030262

See end of article for authors' affiliations

.....................

Correspondence to: Professor S T Holgate, Allergy and Inflammation Research, Southampton General Hospital, Southampton SO'16 6YD, UK; sth@soton.ac.uk

Received 16 June 2004 Accepted 10 March 2005

\begin{abstract}
Background: In adult asthma the bronchial epithelium shows high expression of the epidermal growth factor receptor (EGFR) and the cyclin dependent kinase inhibitor, p2 $1^{\text {waf, }}$, linked to ongoing stress and injury.

Methods: To determine if these are early markers of disease, sections of bronchial specimens obtained post mortem or by bronchoscopy from non-asthmatic $(n=7)$, moderate $(n=7)$, or severe $(n=9)$ asthmatic children aged 5-15 years were examined immunohistochemically. All severe and one moderately asthmatic children were receiving inhaled corticosteroids.

Results: The lamina reticularis of the asthmatic biopsy sections was found to be thicker $(p=0.01)$ than normal with increased deposition of collagen III $(p=0.007)$; submucosal eosinophil numbers did not differ between groups. As in adults, there was an asthma-related increase in epithelial EGFR $(p<0.002)$ but there was no evidence of proliferation, with Ki67 being reduced $(p=0.001)$ and $p 21^{\text {waf }}$ increased $(p<0.004)$. The thickness of the lamina reticularis was significantly correlated with epithelial EGFR (rho $=0.77, \mathrm{p}<0.001$ ).

Conclusions: These data provide evidence that, in asthmatic children, the epithelium is stressed or injured without significant eosinophilic inflammation. This change in the epithelial phenotype is associated with collagen deposition in the lamina reticularis, suggesting that the epithelial mesenchymal trophic unit is active early in, and may contribute to, the pathogenesis of asthma.
\end{abstract}

A sthma is increasing in prevalence worldwide and represents a significant economic burden. Despite advances in defining the inflammatory and immunological components of asthma, there is relatively little understanding of the cellular and molecular mechanisms underlying the structural changes seen in the asthmatic lung (airway remodelling). These changes, which include epithelial goblet cell metaplasia and hyperplasia, collagen deposition and thickening of the subepithelial lamina reticularis, increased matrix deposition throughout the airway wall, smooth muscle hyperplasia and hypertrophy, microvascular and neurite proliferation, are consistently observed in ongoing disease as well as asthmatic airways post mortem. ${ }^{1-4}$ Airway remodelling has been linked to bronchial hyperresponsiveness (BHR) to diverse triggers and a steeper trajectory of long term decline in lung function in adult asthma..$^{5-7}$ In established asthma these structural and accompanying functional changes are poorly responsive to corticosteroids. Although with prolonged treatment some improvement in BHR is evident, ${ }^{8}$ in those with moderate to severe disease it almost always remains abnormal.

Until recently airway remodelling has been considered to be a secondary phenomenon, developing late in the disease process as a consequence of persistent inflammation. It has therefore received less attention than the inflammatory component and its relevance to disease pathogenesis is still controversial. However, the importance of tissue remodelling as an early and consistent component of childhood asthma has been emphasised in a recent biopsy study which described collagen deposition in the lamina reticularis and underlying fibroblast proliferation rather than eosinophil infiltration as consistent features of the disease. ${ }^{9-11}$ Furthermore, airway biopsy studies in young children have shown tissue restructuring up to 4 years before asthma diagnosis, ${ }^{12}$ indicating that this process begins early in the development of asthma and may occur in parallel with or even be required for the establishment of persistent inflammation.

Thickening of the lamina reticularis is diagnostic of asthma and reflects events linked to thickening of the entire airway wall. ${ }^{13}$ In 1990 we described a layer of subepithelial mesenchymal cells with features of myofibroblasts whose number was increased in asthma in proportion to the thickness of the lamina reticularis..$^{14}$ More recently we have shown that epithelial epidermal growth factor receptor (EGFR) expression in asthma is positively correlated with the thickness of the lamina reticularis, ${ }^{15}$ thereby linking epithelial activation and/or injury to the underlying myofibroblast activity. This link is supported by in vitro studies in which injury or mechanical stretching of epithelial monolayers results in increased release of fibroproliferative and fibrogenic growth factors ${ }^{16}{ }^{17}$ whose levels are also increased in asthma. ${ }^{18} 19$ Extending these studies into a co-culture model, polyarginine or mechanical damage to confluent monolayers of bronchial epithelial cells grown on a collagen gel seeded with human myofibroblasts leads to enhanced proliferation and increased collagen gene expression from the combined effects of fibroblast growth factor (FGF)-2, insulinlike growth factor (IGF)-1, platelet derived growth factor (PDGF)-BB, transforming growth factor (TGF)- $\beta$, and endothelin (ET)-1. ${ }^{16}$ These observations have led us to postulate that the epithelial mesenchymal trophic unit (EMTU) plays a key role in initiating airway remodelling in asthma as a result of abnormal epithelial injury and repair. ${ }^{20}$

Recognising the importance of epithelial mesenchymal signalling in physiological and pathological remodelling responses, we hypothesised that the structural changes in the lamina reticularis of asthmatic children are linked to

Abbreviations: BHR, bronchial hyperresponsiveness; EGFR, epidermal growth factor receptor; EMTU, epithelial mesenchymal trophic unit; $\mathrm{FEV}_{1}$, forced expiratory volume in 1 second; PEF, peak expiratory flow 
epithelial injury as we and others have observed in adult asthma. ${ }^{15}$ The purpose of the present study was to examine the bronchial epithelium of normal and asthmatic children for the presence of markers of epithelial stress and repair and to relate these to markers of Th2-mediated inflammation (eosinophils) and remodelling (collagen deposition). Specifically, this involved detection of (1) EGFR whose expression in adult asthma increases according to disease severity, is insensitive to corticosteroids, and is evident throughout the epithelium indicating widespread stress or damage; ${ }^{15}$ (2) the cyclin/cyclin dependent kinase (CDK) inhibitor p2 $1^{\text {waf }}$ whose expression is increased in adult asthma, particularly at the severe end of the disease spectrum $^{21}$ and also indicating ongoing stress or injury; and (3) the proliferation marker Ki67 to assess the extent of epithelial restitution.

\section{METHODS \\ Subjects}

Twenty three asthmatic children aged 5-15 years were enrolled into the study. The diagnosis of asthma and its severity were made according to the GINA guidelines ${ }^{22}$ and the Russian National Program for the management and prevention of asthma in childhood..$^{23}$ Written informed consent was obtained from the children's parents and the protocol was approved by the ethics committee of the Chelyabinsk City Hospital and the Russian Medical Association. The primary purpose of the procedure was for clinical investigation to examine the airway pathology in order to guide management for the individual. Reasons for investigation included suspicion of an undetected bacterial or fungal infection, foreign body aspiration, gastro-oesophageal reflux, or to exclude congenital malformations (for example, tracheomalacia and bronchomalacia) with a view to establishing a clear diagnosis and treatment strategy. In general, approx $3-4 \%$ of asthmatic children who undergo bronchoscopy at the Chelyabinsk City Hospital have an associated diagnosis and $1-2 \%$ an alternative diagnosis. There were no changes in medication before bronchoscopy and, at the time of study, the children were classified as being in a stable phase of their disease.

The asthmatic biopsy specimens were compared with bronchial tissue obtained from seven non-asthmatic children with no history of atopy (allergic rhinitis, conjunctivitis or eczema) who had met their death in road traffic accidents. These post mortem samples were acquired with approval from the ethics committee of the Chelyabinsk City Hospital and the Russian Medical Association and written informed consent from the parents of the dead child. Samples were obtained within 2 hours of death and were obtained by whole airway section from the carinae between the right
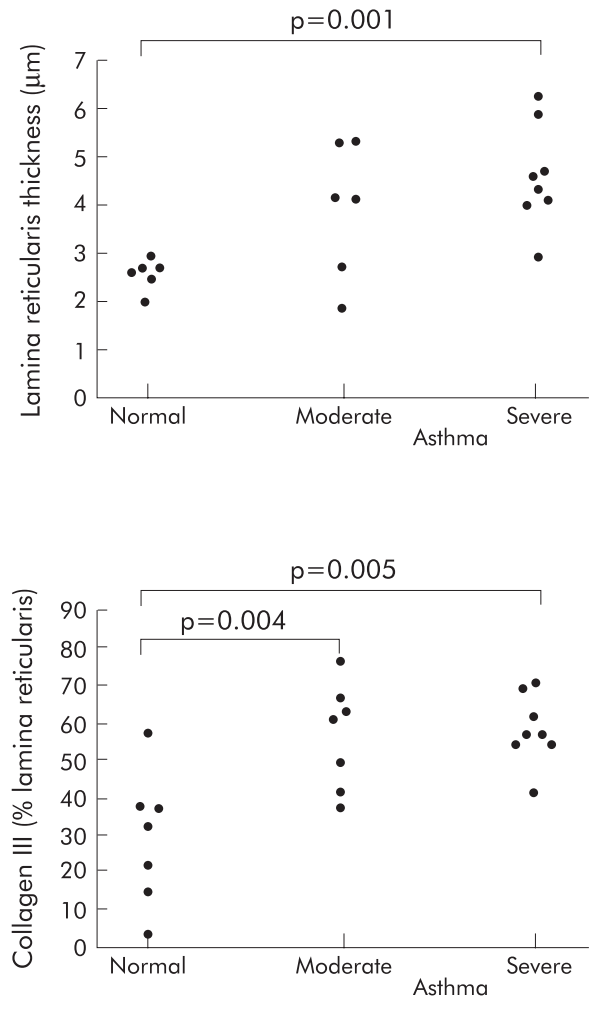

Figure 1 Quantitative analysis of the thickness of the lamina reticularis (top panel) and collagen deposition in the subepithelial basement membrane region (bottom panel) of bronchial mucosa from normal and asthmatic children.

middle and lower lobes, as for the asthmatic biopsies. They were transferred into $10 \%$ formalin and processed in an identical fashion to the asthmatic biopsies.

\section{Bronchoscopy}

Rigid bronchoscopy was undertaken under general anaesthesia using a Friedel (Berlin, Germany) rigid bronchoscope. At this time, fibreoptic bronchoscopy was not available at the Chelyabinsk Hospital. The procedure was conducted in accordance with safety criteria laid down in the recent guidelines described for fibreoptic bronchoscopy. ${ }^{24}$ A single mucosal biopsy specimen was taken from the carinae between the right middle and lower lobes. The biopsy specimen was carefully removed and transferred to $10 \%$ formalin fixative for processing into paraffin.

\begin{tabular}{|c|c|c|c|}
\hline & $\begin{array}{l}\text { Controls } \\
(n=7)\end{array}$ & $\begin{array}{l}\text { Moderate asthma } \\
(n=7)\end{array}$ & $\begin{array}{l}\text { Severe asthma } \\
(n=9)\end{array}$ \\
\hline Mean (range) age (years) & $10.3(5-15)$ & $9.2(5-15)$ & $9.9(7-13)$ \\
\hline Mean (range) duration of asthma (years) & - & $4.1(0.2-11)$ & $6.9(0.3-11)$ \\
\hline Sex (M:F) & $6: 1$ & $4: 3$ & $4: 5$ \\
\hline \multicolumn{4}{|l|}{ Treatment } \\
\hline Inhaled corticosteroids & - & 1 & 9 \\
\hline Budesonide & & $400 \mu \mathrm{g}$ & $800-1000 \mu \mathrm{g}$ \\
\hline Sodium cromoglicate & - & 7 & No treatment \\
\hline Long acting $\beta_{2}$ agonists & & 2 & 4 \\
\hline Sustained release theophylline & & - & 3 \\
\hline Mean (SD) FEV (\% predicted) & $\mathrm{NA}^{*}$ & $77.3(22.2)$ & $58.4(17.3)$ \\
\hline Mean (SD) PEF (\% predicted) & $\mathrm{NA}^{*}$ & $79.4(21.1)$ & $59.2(9.9)$ \\
\hline Median (range) total serum lgE (units/ml) & $\mathrm{NA}^{*}$ & $375(43-1917)$ & $1404(36-3099)$ \\
\hline
\end{tabular}

$\mathrm{FEV}_{1}$, forced expiratory volume in 1 second; PEF, peak expiratory flow. *These children had no previous history of asthma or atopy. 
Table 2 Global results of immunohistochemical analysis

\begin{tabular}{|c|c|c|c|c|}
\hline & $\begin{array}{l}\text { Controls } \\
\text { ( } n=6 \text { or } 7 \text { ) }\end{array}$ & $\begin{array}{l}\text { Moderate asthma } \\
(n=6 \text { or } 7)\end{array}$ & $\begin{array}{l}\text { Severe asthma } \\
(n=9)\end{array}$ & p value ${ }^{*}$ \\
\hline $\begin{array}{l}\text { Lamina reticularis } \\
(\mu \mathrm{m})\end{array}$ & $2.60(2.46-2.65)$ & $4.11(3.02-4.96)$ & $4.41(4.02-4.96)$ & 0.01 \\
\hline $\begin{array}{l}\text { Submucosal collagen } \\
\text { III (\%) }\end{array}$ & $32.2(18.0-36.7)$ & $60.4(44.9-64.4)$ & $56.4(53.5-61.1)$ & 0.007 \\
\hline $\begin{array}{l}\text { Submucosal EG2 } \\
+ \text { ve }\left(\text { cells } / \mathrm{mm}^{2}\right)\end{array}$ & $16.9(13.7-75.5)$ & $30.9(14.7-71.6)$ & $41.4(19.7-105.8)$ & 0.692 \\
\hline $\begin{array}{l}\text { EGFR (\% intact } \\
\text { epithelium) }\end{array}$ & $47.4(46.4-49.7)$ & $86.4(79.8-89.9)$ & $86.4(83.3-89.4)$ & 0.002 \\
\hline $\begin{array}{l}\text { p21 (\% intact } \\
\text { epithelium) }\end{array}$ & $23.7(16.8-41.0)$ & $82.5(75.3-87.4)$ & $87.9(81.0-89.0)$ & 0.004 \\
\hline $\begin{array}{l}\text { MIB-1 (\% intact } \\
\text { epithelium) }\end{array}$ & $26.3(17.9-27.7)$ & $2.3(1.2-5.1)$ & $0.9(0.17-2.0)$ & 0.001 \\
\hline
\end{tabular}

Data are shown as median (interquartile range).

*Analysis of variance using the Kruskal-Wallis rank test.

\section{Immunohistochemistry}

All embedded tissue samples were initially cut and stained using the haematoxylin and eosin method to assess suitability for immunohistochemistry. To be included for immunohistochemical staining, samples had to have an analysable submucosal area of at least $0.42 \mathrm{~mm}^{2}$ and epithelial length of $0.8 \mathrm{~mm}^{25}$ Of the samples initially analysed, all seven normal tissue samples, seven of nine moderate asthma biopsies and nine of 14 severe asthma biopsies were suitable. The clinical characteristics of each group are shown in table 1 .

Five micron sections were cut and stained immunohistochemically using the streptavidin biotin peroxidase technique with the following antibodies: a sheep anti-EGFR polyclonal antibody (an IgG fraction of immune serum raised against affinity purified EGFRs), mouse anti-p2 $1^{\text {waf }}$ (Santa Cruz, CA, USA), mouse anti-Ki67 (MIB-1, Dako, Ely, UK), mouse anti-collagen III (Chemicon, Harrow, UK), and mouse anti-eosinophil cationic protein (EG2, Pharmacia Upjohn,
Milton Keynes, UK) which recognises eosinophils in formalin fixed tissue, irrespective of activation state. ${ }^{26}$ We elected to use Ki67 as a marker of proliferation as other markers such as proliferating cell nuclear antigen have been shown to be expressed in DNA repair. In contrast, the Ki67 (MIB-1) antibody has been shown to correlate with semi-conservative DNA synthesis rather than excision repair DNA synthesis. ${ }^{27}$ For the antibodies used, their specificity and lack of cross reactivity were demonstrated in our previous studies; ${ }^{15} 21$ isotype matched antibody controls were also included in each staining run and were negative. Immunostaining for EGFR, p21, and Ki67 was quantified by computer assisted image analysis (KS400, Image Associates, Thame, UK) as described in the supplement available online at the Thorax website (http://www.thoraxjnl.com/supplemental).

\section{Statistical analysis}

Data were not normally distributed and are presented as medians and interquartile ranges. Statistical analyses were
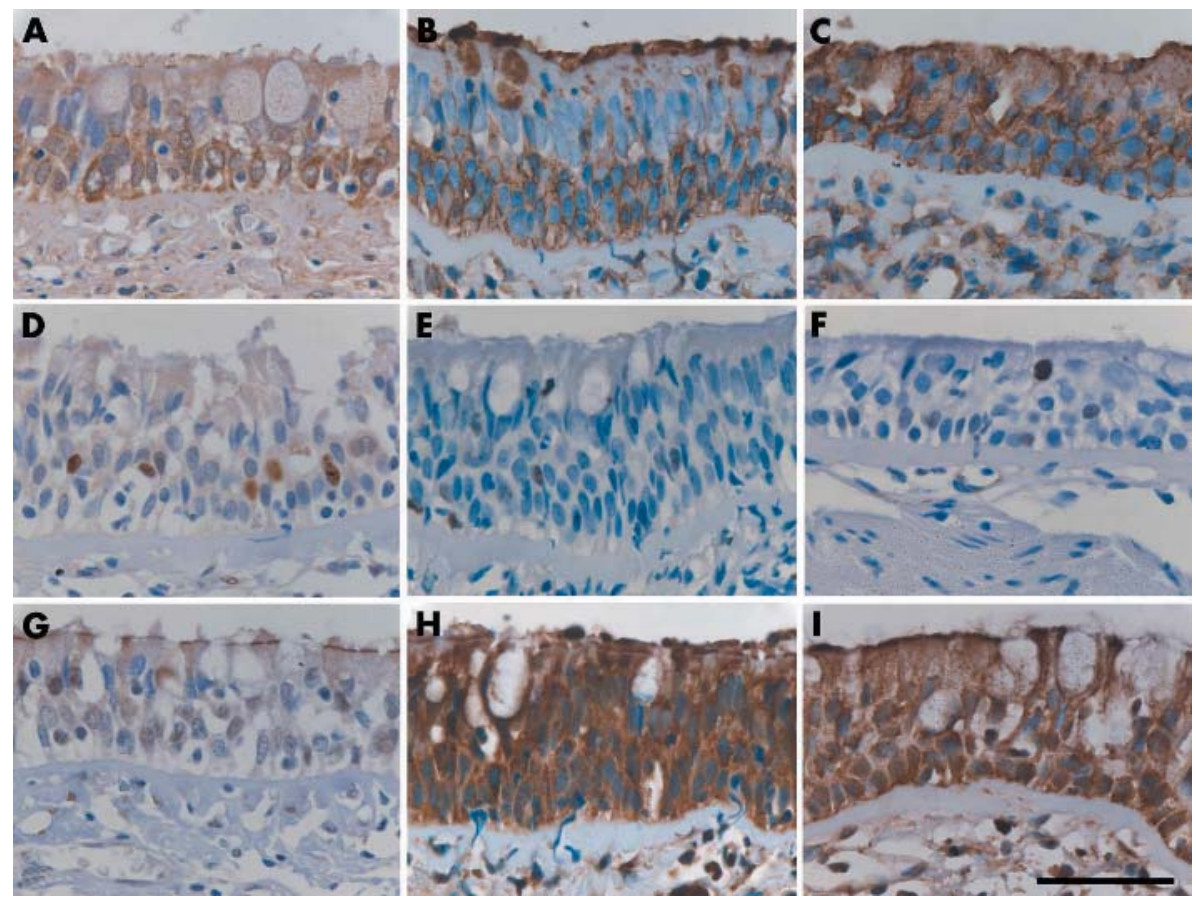

Figure 2 Typical pattern of immunostaining showing epithelial EGFR (A-C), Ki67 (D-F), and p2 ${ }^{\text {waf }}$ (G-I) expression in bronchial mucosa of a normal subject $(A, D, G)$, a subject with moderate asthma $(B, E, H)$, and one with severe asthma $(C, F, I)$. Note also the relative thickness of the lamina reticularis in these tissue sections. 


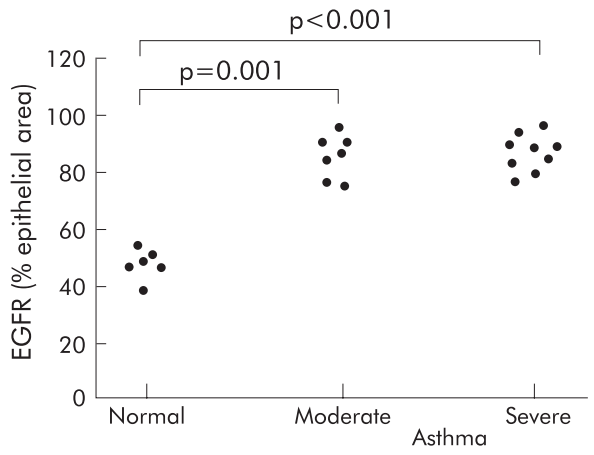

Figure 3 Quantitative analysis of epithelial EGFR immunostaining as determined with computer aided image analysis.

performed using the Kruskal-Wallis test and then pairwise comparisons were made using the Mann-Whitney U test, where appropriate. No corrections were made for multiple testing. Correlations were examined using Spearman's rank correlation test. A $p$ value of $<0.05$ was considered significant.

\section{RESULTS}

Clinically indicated bronchoscopies in children have been performed at the Chelyabinsk City Clinical Hospital since 1967. Rigid bronchoscopy was undertaken under general anaesthesia to ensure that this invasive procedure could be completed successfully with minimal discomfort to the child; the procedure was performed expeditiously with careful monitoring (oxygen saturation and electrocardiogram, noninvasive blood pressure). The bronchoscopy was found to be safe and well tolerated; no complications were encountered.

The lamina reticularis in the bronchial biopsy specimens of the asthmatic children was thicker than normal (table 2 and fig 1, top panel); this was accompanied by a significant increase in staining for interstitial collagen III (fig 1, bottom panel). The measured thickness of the lamina reticularis in the asthmatic and control cases was similar to previous reports, ${ }^{9-1128}$ suggesting that the difference between the asthmatic and non-asthmatic groups was unlikely to result from differences in tissue processing (biopsy versus whole airway section in asthmatic and control cases, respectively). As also reported previously, ${ }^{9-11} 28$ there were no significant differences in eosinophil numbers between any of the groups. The median (IQR) EG2+ eosinophils $/ \mathrm{mm}^{2}$ of submucosa were 16.9 (13.7-75.5) for normal children, 30.9 (14.7-71.6) for

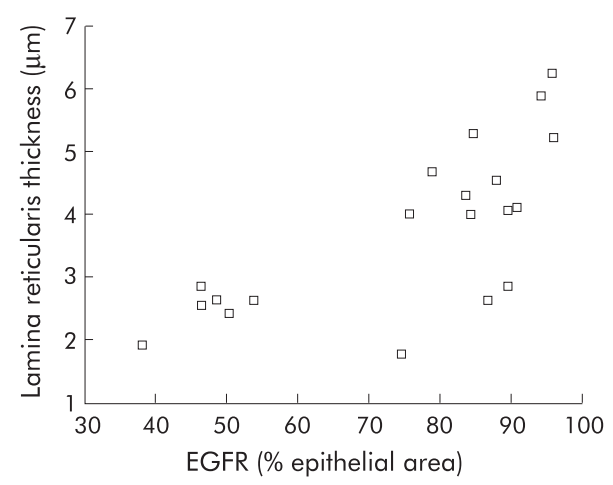

Figure 4 Correlation between epithelial EGFR expression and the thickness of the lamina reticularis. Data were analysed using Spearman's rank correlation.
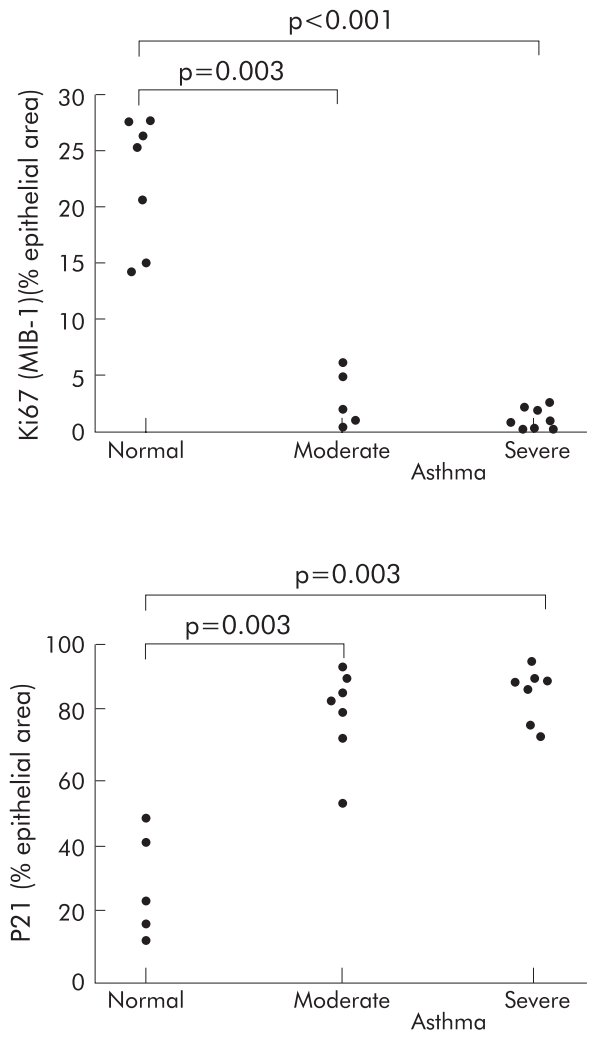

Figure 5 Quantitative analysis of Ki67 and p2 $1^{\text {waf }}$ immunostaining in intact bronchial epithelium.

children with moderate asthma, and 41.4 (19.7-105.8) for severely asthmatic children (table 2 ).

Immunohistochemical analysis of EGFR expression in the airway mucosa from non-asthmatic children revealed positive epithelial staining which was associated with cell membranes and confined to the basal cells of the epithelium and lateral junctions between the columnar cells; no staining was evident on the luminal surface of the epithelium (fig 2A), as we have observed in normal adult bronchial epithelium. ${ }^{15}$ Bronchial epithelium from children with moderate asthma showed a similar pattern of staining, but the amount of staining was increased and occasional goblet cells also showed intense immunostaining (fig 2B). In severe asthma EGFR immunostaining was both more intense and occurred throughout the epithelium, as we have reported in adult severe asthma. The increased staining in the columnar epithelial cells was frequently associated with goblet cells (fig 2C) and showed intense staining of the whole cell. Epithelial immunostaining increased with disease severity (fig 3), extending into the columnar as well as the basal cells and was positively correlated with subepithelial collagen III deposition ( $r h o=0.47, p<0.03$ ) and the thickness of the lamina reticularis (rho $=0.77, \mathrm{p}<0.00 \mathrm{l}$; fig 4 ), as we have also reported in adult disease. There were no significant correlations between eosinophil numbers and either EGFR expression or the thickness of the lamina reticularis.

To explore the relevance of EGFR upregulation we further analysed expression of the proliferation marker Ki67 (fig 2DF) and the cell cycle inhibitor p2 $1^{\text {waf }}$ (fig 2G-I). Immunostaining for Ki67 was mostly restricted to the basal cells and was significantly decreased in the asthmatic bronchial epithelium compared with normal controls $\left(\mathrm{p} \leqslant 0.003\right.$; fig 5 top panel). In contrast, $\mathrm{p} 21^{\text {waf }}$ expression was markedly and significantly increased in asthma 
( $p=0.003$; fig 5 bottom panel), with staining of the columnar and basal cell layers. There were significant negative correlations between Ki67 and p2 $1^{\text {waf }}$ (rho $=-0.65, p=0.007)$ and subepithelial collagen III expression (rho $=-0.66, p=0.001)$. In contrast, there was a positive correlation between EGFR and p2 $1^{\text {waf }}(r=0.58$, $\mathrm{p}=0.009$ ). There were no significant correlations between eosinophil numbers and either $2 \mathrm{1}^{\text {waf }}$ or Ki67.

\section{DISCUSSION}

A number of non-invasive approaches can be used to study components of the asthmatic phenotype in children, but at present we do not know how these relate to bronchial histology, particularly to airway remodelling. While recognising that obtaining biopsy specimens from children at bronchoscopy is a very serious procedure, sampling can be performed safely under general anaesthetic and was found to be safe, well tolerated, and free of complications, as previously reported. ${ }^{29-31}$ In accordance with ethical guidelines, all children who entered the study were undergoing bronchoscopy for clinical investigation, and only where it was deemed safe was parental consent obtained to take an additional biopsy for research purposes. While a single biopsy specimen may not give a true representation of the whole airway, studies in adults ${ }^{24}$ and children $^{28}$ suggest that variability between subjects is considerably greater than variability between biopsies taken from the same subject at any one time.

The use of bronchoscopy to obtain airway biopsies in children with significant lung disease has recently been reviewed. ${ }^{32}$ At present it is only ethical to undertake such a procedure if it is indicated for a clinical purpose to establish a clear diagnosis and to exclude causes of wheezing other than asthma. Renal and liver biopsies, used to establish clear pathological patterns of disease, led to the improved management of such disorders as glomerular nephritis and hepatitis. In the case of airway disease, the recognition of the importance of early life in the origins of diseases such as chronic asthma, with a lifelong requirement for corticosteroids which may or may not produce long term benefit, indicate genuine need to understand more about the pathology of disorders affecting the conducting airways. The classification of childhood airway diseases by pathological criteria will undoubtedly have therapeutic implications. Although we cannot exclude the possibility that the changes in the group with severe asthma may be related to disease duration and progression, the demonstration of a chronic wound scenario in severe childhood asthma is highly relevant and moves the discussion of chronic forms of the disease from re-modelling to pre-modelling of the airways.

Although histological evidence for structural changes in the airways of asthmatic children ${ }^{9-12}$ and young adults with $\mathrm{BHR}^{33}$ has been reported previously, we provide the first evidence that there are phenotypic abnormalities of the juvenile asthmatic bronchial epithelium that mirror those seen in adult disease. Most significantly, we show that EGFR expression is upregulated in the bronchial epithelium of children with asthma and, as in adult asthma, there is minimal evidence of increased proliferation..$^{21}{ }^{34}$ However, unlike adult asthmatic epithelium whose proliferation index was not significantly different from normal, the level of Ki67 staining in paediatric asthma was markedly lower than normal, suggesting a significant suppression of bronchial epithelial proliferation. While this difference may reflect the small sample size used in the present study, another explanation for the low level of proliferation may be increased expression of the cell cycle inhibitor $\mathrm{p} 21^{\text {waf }}, 1$ which was also found in the present study. Alternatively, the lack of proliferation may be due to an insufficiency of the mitogenic stimulus, as has been described in ventilated infants who develop chronic lung disease of prematurity or respiratory distress syndrome. In these infants, bronchoalveolar lavage fluid levels of epidermal growth factor are lower than in control ventilated infants. ${ }^{35}$ Considering that impaired lung growth is associated with persistent wheezing in childhood, ${ }^{36}$ this lack of proliferation may represent an important lesion that merits further detailed investigation. Recognising the growth effects of corticosteroids in vivo ${ }^{37}$ and in vitro, ${ }^{38}$ an obvious possibility that needs to be further explored is the impact of treatment on the bronchial epithelium.

While atopy is a strong risk factor for asthma, we have highlighted the importance of locally acting tissue susceptibility factors that occur in parallel with Th2 inflammation to give rise to the development of chronic asthma. ${ }^{39}{ }^{40}$ According to this model, susceptibility to tissue injury is a major factor that contributes to persistent inflammation and airways remodelling and this interacts with Th2 cytokines to augment the responses. In support of such a concept, we have previously shown that asthmatic epithelial cells are more susceptible to oxidant-induced apoptosis ${ }^{41}$ and that oxidant stress leads to high cytoplasmic expression of $\mathrm{p} 21^{\text {waf }}{ }^{21}$ The high level of cytoplasmic p2 $1^{\text {waf }}$ in paediatric asthma is strongly suggestive of a stressed epithelium and, by extrapolation, may reflect susceptibility to oxidants as in adult disease. Such a phenotypic abnormality would explain epidemiological data linking air pollution and diets low in antioxidants with asthma exacerbations. ${ }^{40}$

Although it has been postulated that airway "remodelling" is a long term consequence of chronic airway inflammation, our data showing excess deposition of interstitial collagen in the lamina reticularis indicate that these changes occur relatively early in life. Furthermore, our data are consistent with four previous reports ${ }^{9-11} 28$ which showed no requirement for concurrent eosinophilic inflammation for thickening of the subepithelial reticular basement membrane. This suggests a dissociation between at least some of the inflammatory and "remodelling" events in asthma, although we cannot completely exclude the possibility that there may have been a past history of eosinophilic inflammation in these asthmatic children. In the Childhood Asthma Management Program (CAMP) in which children aged 511 years were treated for 4-6 years with the inhaled corticosteroid budesonide, there was no long term effect of inhaled corticosteroids on the post-bronchodilator improvement in $\mathrm{FEV}_{1}{ }^{42}$ Similarly, in the START study, early introduction of inhaled corticosteroids did not reverse the decline in post-bronchodilator $\mathrm{FEV}_{1}{ }^{43}$ One explanation for these findings may be the occurrence of airway "remodelling", as observed in the present study in children with moderately severe asthma who were receiving regular corticosteroid therapy.

While the presence of eosinophils may have been suppressed in children with severe asthma due to their use of corticosteroids, structural changes were apparent in the lamina reticularis of the asthmatic children irrespective of eosinophil numbers. However, it is noteworthy that the thickness of the lamina reticularis was correlated with epithelial EGFR levels, as previously reported in adult asthma. ${ }^{15}$ Since we have found that epithelial EGFR and IL8 expression in adults with severe asthma are strongly correlated, ${ }^{44}$ it is possible that an EGFR mediated influx of neutrophils contributes to airway dysfunction in paediatric asthma. This proposal is consistent with recent reports showing epithelial disruption and increased neutrophil numbers in relation to symptom severity. ${ }^{45}{ }^{46}$

Increased expression of the EGFR is consistently observed in response to epithelial injury, suggesting that epithelial 
damage is a feature of paediatric asthma as previously indicated by bronchoalveolar cell profile studies. ${ }^{45}$ Using in vitro models, epithelial injury has been shown to cause increased fibroblast proliferation due to the release of an array of growth factors including FGF, PDGF, ET-1, and TGF $\beta{ }^{16}{ }^{17}$ and this can be augmented by inhibiting EGFR mediated epithelial repair. ${ }^{15}$ Consistent with a role for epithelial mesenchymal signalling in paediatric asthma, epithelial EGFR levels were found to correlate closely with the thickness of the lamina reticularis, as previously reported in adult asthma. ${ }^{15}$ As bidirectional signalling between the epithelium and mesenchyme occurs during branching morphogenesis, it is possible that the "epithelial mesenchymal trophic unit" that controls airway development and maturation is abnormal in asthma and that what we are describing is a consequence of airway "pre-modelling" rather than airway "remodelling".

In conclusion, our data lend support to the view that the early pathological changes in asthma are linked to changes in the local tissue microenvironment related to epithelial stress and injury. This change in the epithelial phenotype is associated with increased collagen deposition in the lamina reticularis, suggesting that the epithelial mesenchymal trophic unit is active early in-and may contribute-to the pathogenesis of asthma.

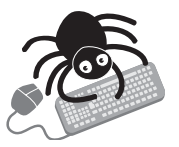

Further details of the immunohistochemical analysis are provided in the online supplement available at the Thorax website (http://www.thoraxjnl.com/ supplemental).

\section{Authors' affiliations}

S J Wilson, D E Davies, S T Holgate, Division of Infection, Inflammation and Repair, School of Medicine, Southampton General Hospital, Southampton SO16 6YD, UK

I A Fedorov, City Clinical Hospital \#1, Chelyabinsk, Russia

The authors have no competing interests to declare.

\section{REFERENCES}

1 Dunnill MS. The pathology of asthma. Ciba Found Study Group 1971:38:35-46.

2 Carroll N, Elliot J, Morton A, et al. The structure of large and small airways in nonfatal and fatal asthma. Am Rev Respir Dis 1993;147:405-10.

3 Jeffery P. Structural alterations and inflammation of bronchi in asthma. Int J Clin Pract Suppl 1998:96:5-14.

4 Busse WW, Banks-Schlegel S, Wenzel SE. Pathophysiology of severe asthma $J$ Allergy Clin Immunol 2000;106:1033-42.

5 Hoshino M, Nakamura Y, Sim JJ. Expression of growth factors and remodelling of the airway wall in bronchial asthma. Thorax 1998;53:21-7.

6 Ward C, Pais M, Bish R, et al. Airway inflammation, basement membrane thickening and bronchial hyperresponsiveness in asthma. Thorax 2002;57:309-16

7 Lange P, Parner J, Vestbo J, et al. A 15-year follow-up study of ventilatory function in adults with asthma. N Engl J Med 1998;339:1 194-200.

8 Sont JK, Willems LN, Bel EH, et al. Clinical control and histopathologic outcome of asthma when using airway hyperresponsiveness as an additional guide to long-term treatment. The AMPUL Study Group. Am J Respir Crit Care Med 1999; 159:1043-51.

9 Cokugras H, Akcakaya N, Seckin, et al. Ultrastructural examination of bronchial biopsy specimens from children with moderate asthma. Thorax 2001;56:25-9.

10 Payne DN, Rogers AV, Adelroth E, et al. Early thickening of the reticular basement membrane in children with difficult asthma. Am J Respir Crit Care Med 2003;167:78-82.

11 Jenkins HA, Cool C, Szefler SJ, et al. Histopathology of severe childhood asthma: a case series. Chest 2003;124:32-41.

12 Pohunek P, Roche WR, Tarzikova J, et al. Eosinophilic inflammation in the bronchial mucosa in children with bronchial asthma. Eur Respir J 2000;11(Suppl 25):160s.

13 James AL, Maxwell PS, Pearce-Pinto G, et al. The relationship of reticular basement membrane thickness to airway wall remodeling in asthma. Am J Respir Crit Care Med 2002;166:1590-5.
14 Brewster CE, Howarth PH, Diukanovic R, et al. Myofibroblasts and subepithelial fibrosis in bronchial asthma. Am J Respir Cell Mol Biol 1990;3:507-11.

15 Puddicombe SM, Polosa R, Richter A, et al. Involvement of the epidermal growth factor receptor in epithelial repair in asthma. FASEB J 2000;14:1362-74

16 Zhang S, Smartt H, Holgate ST, et al. Growth factors secreted by bronchial epithelial cells control myofibroblast proliferation: an in vitro co-culture model of airway remodeling in asthma. Lab Invest 1999:79:395-405.

17 Tschumperlin DJ, Shively JD, Kikuchi T, et al. Mechanical stress triggers selective release of fibrotic mediators from bronchial epithelium. Am J Respir Cell Mol Biol 2003;28:142-9.

18 Redington AE, Madden J, Frew AJ, et al. Transforming growth factor-beta 1 in asthma. Measurement in bronchoalveolar lavage fluid. Am J Respir Crit Care Med 1997:156:642-7.

19 Redington AE, Roche WR, Madden J, et al. Basic fibroblast growth factor in asthma: measurement in bronchoalveolar lavage fluid basally and following allergen challenge. J Allergy Clin Immunol 2001;107:384-7.

20 Holgate ST, Davies DE, Lackie PM, et al. Epithelial-mesenchymal interactions in the pathogenesis of asthma. J Allergy Clin Immunol 2000;105:193-204.

21 Puddicombe SM, Torres-Lozano C, Richter A, et al. Increased expression of p21 (waf) cyclin dependent kinase inhibitor in asthmatic bronchial epithelium. Am J Respir Cell Mol Biol 2003;28:61-8.

22 Bousquet J. Global initiative for asthma (GINA) and its objectives. Clin Exp Allergy 2000;30(Suppl 1):2-5.

23 Strategy of Management and Prevention. Asthma in childhood. National program. Moscow: Strategy of Management and Prevention, 1997.

24 Jeffery P, Holgate S, Wenzel S. Methods for the assessment of endobronchial biopsies in clinical research: application to studies of pathogenesis and the effects of treatment. Am J Respir Crit Care Med 2003;168:S1-17.

25 Sullivan P, Stephens D, Ansari T, et al. Variation in the measurements of basement membrane thickness and inflammatory cell number in bronchial biopsies. Eur Respir J 1998;12:811-5.

26 Jahnsen FL, Halstensen TS, Brandtzaeg P. Erroneous immunohistochemical application of monoclonal antibody EG2 to detect cellular activation. Lancet 1994;344:1514-5.

27 McCormick D, Chong H, Hobbs C, et al. Detection of the Ki-67 antigen in fixed and wax-embedded sections with the monoclonal antibody MIB 1 . Histopathology 1993;22:355-60

28 Payne DN, Qiu Y, Zhu J, et al. Airway inflammation in children with difficult asthma: relationships with airflow limitation and persistent symptoms. Thorax 2004:59:862-9.

29 Bush A, Pohunek P. Brush biopsy and mucosal biopsy. Am J Respir Crit Care Med 2000;162:S18-22.

30 Salva PS, Theroux C, Schwartz D. Safety of endobronchial biopsy in 170 children with chronic respiratory symptoms. Thorax 2003;58:1058-60.

31 Saglani S, Payne DN, Nicholson AG, et al. The safety and quality of endobronchial biopsy in children under five years old. Thorax 2003;58:1053-7.

32 Midulla $F$, de Blic J, Barbato A, et al. Flexible endoscopy of paediatric airways. Eur Respir J 2003;22:698-708.

33 Sue-Chu M, Karjalainen EM, Altraja A, et al. Lymphoid aggregates in endobronchial biopsies from young elite cross-country skiers. Am J Respir Crit Care Med 1998;158:597-601

34 Demoly P, Simony-Lafontaine J, Chanez P, et al. Cell proliferation in the bronchial mucosa of asthmatics and chronic bronchitics. Am J Respir Crit Care Med 1994;150:214-7.

35 Currie AE, Vyas JR, MacDonald J, et al. Epidermal growth factor in the lungs of infants developing chronic lung disease. Eur Respir J 2001;18:796-800.

36 Stick $\mathbf{S}$. The contribution of airway development to paediatric and adult lung disease. Thorax 2000;55:587-94.

37 Pedersen S. Long-term outcomes in paediatric asthma. Allergy 2002;57(Suppl 74):58-74

38 Dorscheid DB, Wojcik K, White SR. Induction of apoptosis of airway epithelial cells by dexamethasone involves a mitochrondial-dependant pathway. Am J Respir Crit Care Med 2000:161:A778.

39 Holgate ST, Davies DE. Airway inflammation and remodelling in asthmacause and effect? The Immunologist 2001;8:131-5.

40 Davies DE, Wicks J, Powell RM, et al. Airway remodelling in asthma-new insights. J Allergy Clin Immunol 2003:111:215-25.

41 Bucchieri F, Puddicombe SM, Lordan JL, et al. Asthmatic bronchial epithelium is more susceptible to oxidant-induced apoptosis. Am J Respir Cell Mol Biol 2002;27:179-85

42 The Childhood Asthma Management Program Research Group. Long-term effects of budesonide or nedocromil in children with asthma. N Engl I Med 2000;343:1054-63.

43 Pauwels RA, Pedersen S, Busse WW, et al. Early intervention with budesonide in mild persistent asthma: a randomised, double-blind trial. Lancet 2003;361:1071-6.

44 Hamilton LM, Torres-Lozano C, Puddicombe SM, et al. The role of the epidermal growth factor receptor in sustaining neutrophil inflammation in severe asthma. Clin Exp Allergy 2003;33:233-40.

45 Marguet C, Jouen-Boedes F, Dean TP, et al. Bronchoalveolar cell profiles in children with asthma, infantile wheeze, chronic cough, or cystic fibrosis. Am J Respir Crit Care Med 1999;159:1533-40.

46 Krawiec ME, Westcott JY, Chu HW, et al. Persistent wheezing in very young children is associated with lower respiratory inflammation. Am J Respir Crit Care Med 2001;163:1338-43. 